\title{
THE EFFECT OF RATIOS AND NUMBERS OF SPERMATOZOA MIXED FROM TWO MALES ON PROPORTIONS OF OFFSPRING
}

\author{
P. A. MARTIN, T. J. REIMERS, J. R. LODGE* \\ AND P. J. DZIUK \\ Departments of Animal Science and ${ }^{*}$ Dairy Science, University of Illinois, \\ Urbana, Illinois 61801, U.S.A.
}

(Received 30th May 1973)

\begin{abstract}
Summary. When mixtures of semen containing an equal number of spermatozoa from two males are inseminated, the males usually sire disproportionate numbers of the offspring. In this study, when a mixture of equal numbers of spermatozoa from a Columbian (C) and a Leghorn $\left(\mathrm{L}_{1}\right)$ cock was inseminated, the $\mathrm{C}$ male sired $34 \%$ of the offspring. The proportion of offspring was constant regardless of age of males, season, total number of spermatozoa, breed of hen or the interval from insemination to the time of egg-lay over a 15-day period after insemination. The proportion of $\mathbf{C}$ offspring observed from inseminating nine different ratios of spermatozoa arranged progressively from $1 \mathrm{C}: 9 \mathrm{~L}$, $2 \mathrm{C}: 8 \mathrm{~L}$ and so on, was $10 \%, 20 \%, 23 \%, 34 \%, 38 \%, 44 \%, 58 \%, 74 \%$ and $82 \%$. These results were in close agreement with mathematically derived estimates. It appears that the relationship between sperm ratios and the proportions of offspring sired by two males competing heterospermically is dependent on the ratio of the number of competing spermatozoa but not on total number, season, breed of hen or the interval from insemination to fertilization.
\end{abstract}

\section{INTRODUCTION}

When different males are mated in rapid succession to a female without accounting for numbers of spermatozoa from each male, one male usually sires a disproportionate number of offspring (Cole \& Davis, 1914; Dunn, 1927; Roberts \& Dawson, 1935; Sumption, 1961; Dziuk, 1965). When equal volumes of semen or numbers of spermatozoa from two males are mixed before artificial insemination, the proportion of offspring is still quite disparate in mammals (Beatty, 1957, 1960; Edwards, 1965; Roche, Dziuk \& Lodge, 1968; Beatty, Bennett, Hall, Hancock \& Stewart, 1969; O'Reilly, Graves \& Dziuk, 1972) and birds (Bonnier \& Trulsson, 1939; Allen \& Champion, 1955). Heterospermic mixtures containing an equal number of spermatozoa from each male have been used to measure the relative fertility of males (Beatty, 1960; Beatty et al., 1969; Stewart, Spooner, Bennett, Beatty \& Hancock, 1974), effect of semen storage (Roche et al., 1968) and semen extenders 
(O'Reilly et al., 1972), but little is known of the manner in which different total numbers and ratios of spermatozoa might affect heterospermic dominance.

The purpose of this study was to examine the effect of season, total number of spermatozoa, interval from insemination to fertilization, breed of female and various ratios of spermatozoa from two different males on the proportion of offspring sired by those males.

\section{MATERIALS AND METHODS}

Two of the experimental males were from the University of Illinois White Leghorn strain (L) which is purebreeding for the dominant inhibitor gene for colour and for the recessive, fast feathering trait. Males $L_{1}$ and $L_{2}$ were used in competition with a single Columbian male $(\mathrm{C})$, which was homozygous dominant for slow feathering. Hens were of the same $L$ and $G$ strains. Hens were caged individually in numbered laying batteries and the cocks were in individual large cages. All birds had free access to feed and water and were on a schedule of 12-hr light/12-hr dark.

Semen was collected by abdominal massage (Burrows \& Quinn, 1939). The concentration of spermatozoa was determined with a haemocytometer. Random semen samples were examined microscopically for motility. Each semen sample was extended separately with Locke's solution and appropriate volumes of extended $\mathrm{C}$ and $\mathrm{L}$ semen were mixed in a third vial to give the desired numerical ratio of spermatozoa. Semen mixtures were inseminated into the distal portion of the vagina with a $100-\mu \mathrm{l}$ or $0.25-\mathrm{ml}$ syringe.

Eggs from inseminated hens were collected daily beginning $48 \mathrm{hr}$ after insemination for a period of 15 days for Exps I, II and III, and for 10 days for Exps IV, V and VI. The date and the hen number were recorded on each egg. Eggs were stored at $5^{\circ} \mathrm{C}$ and at weekly intervals the accumulated eggs were set in an incubator. Fertilization rates were estimated by candling the eggs for the presence of embryos on Day 7 of incubation. On Day 19 of incubation, eggs were placed in individual containers for hatching.

When the mothers were $L$ hens, paternity was established at the time of hatching by examining the wing tips for fast and slow feathering characteristics. Chicks were individually identified by wing bands and re-examined at 5 or 6 days of age to confirm the initial designation. When $C$ hens were the mothers, paternity of the chicks was determined by examining each chick for colour and feathering characteristics four times at 7-day intervals after hatching. The genetic homozygosity of the males was verified several times during the experimental period by homospermic inseminations.

Experiment I was conducted in May 1971, and consisted of eighty L hens allocated to three groups. Each group was inseminated with different mixtures of semen containing $300 \times 10^{6}$ spermatozoa in one of three different ratios. The ratio of spermatozoa was $1 \mathrm{C}: 2 \mathrm{~L}_{1}$ for Group $1,1 \cdot 5 \mathrm{C}: 1 \cdot 5 \mathrm{~L}_{1}$ for Group 2 and $2 \mathrm{C}: 1 \mathrm{~L}_{1}$ for Group 3. Experiment II was conducted in September 1971, using the same procedure with sixty-four $\mathrm{L}$ hens.

In Exp. III, three groups of ten $\mathbf{L}$ hens each were inseminated with mixtures of spermatozoa containing a total of $100 \times 10^{6}, 200 \times 10^{6}$ or $300 \times 10^{6}$ sperma- 
tozoa in the ratio of $1 \mathrm{C}: 1 \mathrm{~L}_{1}$. One semen mixture was prepared from one $\mathrm{C}$ ejaculate and one $L_{1}$ ejaculate and the three different numbers of spermatozoa were inseminated from the one mixture. Thus, the volume of each insemination was proportional to the total number of spermatozoa inseminated. In the groups of hens receiving $100 \times 10^{6}$ spermatozoa, each cock contributed $50 \times 10^{6}$ spermatozoa which may be a limiting number for fertility. Therefore, Exp. IV was conducted to determine the proportion of eggs that would be fertilized from sixty-four homospermic inseminations each containing $40 \times 10^{6} \mathrm{C}$ or $\mathrm{L}_{1}$ spermatozoa.

In Exp. $V$, twenty-eight $G$ hens and twenty-eight $L$ hens were each inseminated with $100 \times 10^{6}$ spermatozoa in a mixture of $1 \mathrm{C}: 1 \mathrm{~L}_{1}$. The $\mathrm{G}$ hens and $L$ hens were inseminated alternately from a single semen mixture prepared for each of two pairs of ejaculates.

The results of Exps I and II indicated that a mathematical relationship might exist between ratios of $C$ and $L_{1}$ spermatozoa and the resultant proportions of offspring. The basic statistical model, described in some detail by Beatty (1957), assumes that G spermatozoa were $x$ times as heterospermically potent as $L_{1}$ spermatozoa, and the proportions of offspring would vary arithmetically according to the proportion of $\mathrm{C}$ and $\mathrm{L}_{1}$ spermatozoa in the mixtures. Experiment VI tested this hypothesis. A total of $204 \mathrm{~L}$ hens were inseminated with nine sperm mixtures in nine different ratios. Approximately equal numbers of hens in each of the nine groups were inseminated with each mixture of ejaculates collected on a single day. The ratios of spermatozoa from $\mathrm{C}$ and $\mathrm{L}_{1}$ cocks were $1: 9,2: 8,3: 7,4: 6,5: 5,6: 4,7: 3,8: 2$ and $9: 1$. Each hen was inseminated with $100 \times 10^{6}$ spermatozoa. Using this same procedure, $156 \mathrm{~L}$ hens were inseminated with semen mixtures containing spermatozoa from $\mathrm{G}$ and $\mathrm{L}_{2}$.

\section{RESULTS}

In Exp. I, when ratios of spermatozoa were $1 \mathrm{C}: 2 \mathrm{~L}_{1}, 1 \cdot 5 \mathrm{C}: 1 \cdot 5 \mathrm{~L}_{1}$ and $2 \mathrm{C}: 1 \mathrm{~L}_{1}$, the $\mathrm{G}$ male sired $18 \%, 34 \%$ and $43 \%$ of 72,149 and 67 offspring, respectively. In Exp. II, the C cock sired $16 \%, 35 \%$ and $50 \%$ of 117,133 and 158 offspring, respectively, with the same ratios (Table 1). The proportion of offspring from the $\mathrm{C}$ cock for Exps I and II differed significantly $(P<0.005)$ from expected values of $33 \%, 50 \%$ and $67 \%$, assuming that each spermatozoon in the mixture had an equal chance of fertilizing an egg. The relative fertility of the two males as estimated by the maximum likelihood method for Exps I and II was $x=$ $0.465 \pm 0.059$ and $x=0.490 \pm 0.052$, respectively. Differences between the two experiments were not significant $(P>0.05)$ and the pooled $x$ or relative fertility was $x=0.476 \pm 0.039$. In Exps I and II, there were, respectively, eighteen and thirty-two dead embryos whose sire could not be determined, and of the 1154 eggs gathered, $65 \%$ were fertilized.

In Exp. III, when the ratio of spermatozoa was $1 \mathrm{C}: 1 \mathrm{~L}_{1}$ and the total number of spermatozoa was $100 \times 10^{6}, 200 \times 10^{6}$ or $300 \times 10^{6}$, the $\mathrm{C}$ cock sired $21 \%, 43 \%$ and $30 \%$ of 33,42 and 61 chicks, respectively. A test of homogeneity revealed that these proportions did not differ significantly 
$(P>0 \cdot 05)$. The relative potency of the two males was estimated to be $x=$ $0 \cdot 462 \pm 0 \cdot 085$. Paternity could not be established for eight dead embryos. Of the 335 eggs gathered, $43 \%$ were fertilized.

Table 1. Lack of effect of age of cock and season on sire of offspring

\begin{tabular}{|c|c|c|c|c|}
\hline Sperm ratio & Month & $\begin{array}{c}\text { No. of } \\
\text { hens inseminated }\end{array}$ & $\begin{array}{l}\text { No. of } \\
\text { live chicks }\end{array}$ & C offspring \\
\hline $1 \mathrm{C}: 2 \mathrm{~L}_{1}$ & $\begin{array}{l}\text { May } \\
\text { Sept. } \\
\text { Total }\end{array}$ & $\begin{array}{l}20 \\
21 \\
41\end{array}$ & $\begin{array}{r}72 \\
117 \\
189\end{array}$ & $\begin{array}{l}18 \\
16 \\
17^{*}\end{array}$ \\
\hline $1 \cdot 5 \mathrm{C}: 1 \cdot 5 \mathrm{~L}_{1}$ & $\begin{array}{l}\text { May } \\
\text { Sept. } \\
\text { Total }\end{array}$ & $\begin{array}{l}40 \\
21 \\
61\end{array}$ & $\begin{array}{l}149 \\
133 \\
282\end{array}$ & $\begin{array}{l}34 \\
35 \\
34 \uparrow\end{array}$ \\
\hline $2 \mathrm{C}: 1 \mathrm{~L}_{1}$ & $\begin{array}{l}\text { May } \\
\text { Sept. } \\
\text { Total }\end{array}$ & $\begin{array}{l}20 \\
22 \\
42\end{array}$ & $\begin{array}{r}67 \\
158 \\
255\end{array}$ & $\begin{array}{l}43 \\
50 \\
48 \ddagger\end{array}$ \\
\hline
\end{tabular}

C, Columbian cock. $\mathbf{L}_{\mathbf{1}}$, Illinois White Leghorn cock.

* Significantly different from $33 \%(P<0.005)$.

+ Significantly different from $50 \%(P<0.005)$.

$\ddagger$ Significantly different from $67 \%(P<0.005)$.

In Exp. IV, $64 \%$ of 213 eggs laid in a 10-day period were fertilized following homospermic insemination of $40 \times 10^{6}$ spermatozoa from the $\mathrm{C}$ cock and $61 \%$ of 218 eggs were fertilized by the $L_{1}$ cock. Differences in fertility between males were not significant $(P>0.05)$.

In Exp. $\mathrm{V}$, the $\mathrm{G}$ male sired $39 \%$ of the 116 offspring when $\mathrm{C}$ hens were inseminated and $37 \%$ of the 119 offspring when $\mathrm{L}$ hens were inseminated with a $1 \mathrm{G}: 1 \mathrm{~L}_{1}$ sperm mixture. There was no difference in the proportions of offspring sired by the two males due to breed of hens $(P>0.05)$. The relative potency of the two males was estimated to be $x=0 \cdot 610 \pm 0 \cdot 082$. The sire could not be determined for twenty-five and eight dead embryos from $\mathrm{C}$ and $\mathrm{L}$ hens, respectively. The $\mathrm{C}$ hens had $69 \%$ of eggs fertilized and the $\mathrm{L}$ hens had $67 \%$ fertilized.

In Exp. VI when the ratios of spermatozoa from the $\mathrm{C}$ and $\mathrm{L}_{1}$ cocks were $1: 9,2: 8,3: 7,4: 6,5: 5,6: 4,7: 3,8: 2$ or $9: 1$, the $\mathrm{C}$ male sired $10 \%, 20 \%$, $23 \%, 34 \%, 38 \%, 44 \%, 58 \%, 74 \%$ and $82 \%$ of the chicks, respectively (Textfig. 1). The number of chicks observed were $96,99,108,84,77,67,69,93$ and 113 , respectively. The observed values did not differ $(P>0.05)$ from the fitted curve as derived from the estimated relative potency $(x)$ of the two males for this experiment. The estimated $x=0.667 \pm 0.056$ differed $(P<0.05)$ from the pooled estimate $x=0.495 \pm 0.033$ for Exps I, II, III and V. When spermatozoa from the $\mathrm{C}$ male were mixed with spermatozoa from Cock $\mathrm{L}_{2}$, the percentage of offspring sired by the $\mathrm{C}$ male was $3 \%, 10 \%, 23 \%, 16 \%, 43 \%$, $36 \%, 61 \%, 65 \%$ and $76 \%$ for $64,87,56,86,67,75,44,62$ and 58 chicks, respectively (Text-fig. 1). These observed values did not differ $(P>0.05)$ 
C (Columbion)
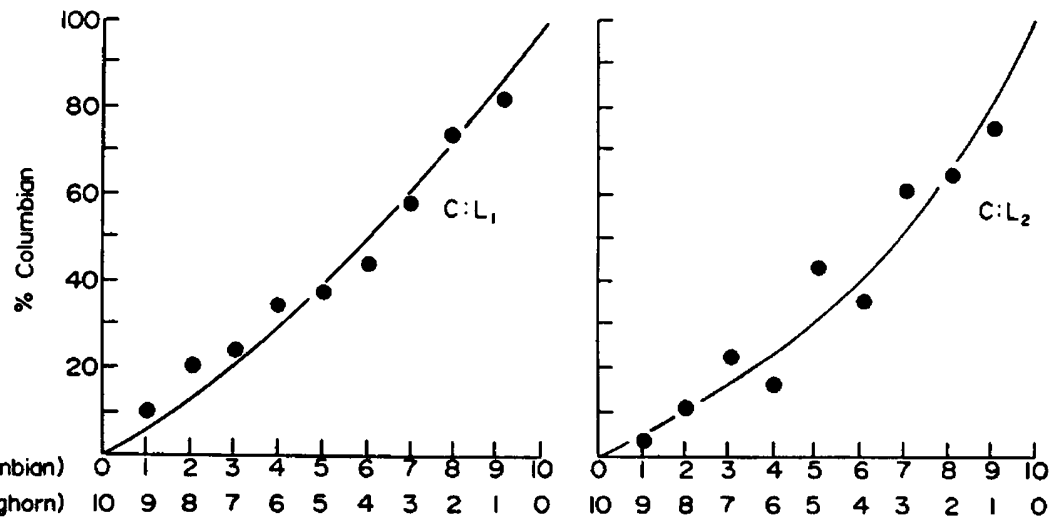

Rotios of spermotozoo

TEXT-Fig. 1. The effect of different ratios of cock spermatozoa on the sire of the offspring.

The observed values $(\bullet)$ did not differ from the calculated curves $(\longrightarrow, P>0.05)$.

from the fitted curve derived from the estimated $x=0.470 \pm 0.047$ for the $\mathrm{C}$ and $L_{2}$ sperm mixtures. For sperm mixtures containing $C$ and $L_{1}$ spermatozoa or $\mathrm{C}$ and $\mathrm{L}_{2}$ spermatozoa, the sire of offspring could not be determined for sixty-four and sixty-eight dead embryos, respectively. Sperm mixtures from $\mathrm{C}$ and $\mathrm{L}_{1}$ cocks and from $\mathrm{C}$ and $\mathrm{L}_{2}$ cocks fertilized $57 \%$ and $75 \%$ respectively, of the eggs collected.

Tests of homogeneity showed that the proportions of offspring in Exps I, II and III were not different $(P>0.05)$ between the three 5-day periods within the 15-day egg-collecting period at each of the sperm ratios tested (Table 2).

Table 2. Lack of effect of time after insemination with mixed cock semen on proportions of offspring from a sire

\begin{tabular}{|c|c|c|c|c|c|c|}
\hline \multirow[b]{3}{*}{ Sperm ratio } & \multicolumn{6}{|c|}{ Days of egg collection after insemination } \\
\hline & \multicolumn{2}{|c|}{2 to 6} & \multicolumn{2}{|c|}{7 to 11} & \multicolumn{2}{|c|}{12 to 16} \\
\hline & $\begin{array}{l}\text { Total no. } \\
\text { of chicks }\end{array}$ & $\begin{array}{l}\% \text { Chicks } \\
\text { sired by } C_{\sigma}\end{array}$ & $\begin{array}{l}\text { Total no. } \\
\text { of chicks }\end{array}$ & $\begin{array}{l}\text { \% Chicks } \\
\text { sired by } C_{\delta}^{\star}\end{array}$ & $\begin{array}{l}\text { Total no. } \\
\text { of chicks }\end{array}$ & $\begin{array}{l}\% \text { Chicks } \\
\text { sired by } C_{0}\end{array}$ \\
\hline $\begin{array}{c}1 \mathrm{C}: 2 \mathrm{~L}_{1} \\
1 \cdot 5 \mathrm{C}: 1 \cdot 5 \mathrm{~L}_{1} \\
2 \mathrm{C}: 1 \mathrm{~L}_{1}\end{array}$ & $\begin{array}{r}92 \\
190 \\
96\end{array}$ & $\begin{array}{l}17 \\
36 \\
45\end{array}$ & $\begin{array}{r}77 \\
132 \\
99\end{array}$ & $\begin{array}{l}16 \\
33 \\
52\end{array}$ & $\begin{array}{l}20 \\
35 \\
30\end{array}$ & $\begin{array}{l}20 \\
29 \\
47\end{array}$ \\
\hline
\end{tabular}

C, Columbian cock. $L_{1}$, Illinois White Leghorn cock.

Values within sperm ratio classes were not significantly different from each other $(P<0.05)$.

The proportion of motile spermatozoa, for the average of two counts of 100 spermatozoa, ranged from $90 \%$ to $96 \%$ for the $\mathrm{C}$ and $\mathrm{L}$ males.

\section{DISCUSSION}

The observation that one male sires a disproportionate number of offspring when an equal number of spermatozoa from two fertile males are mixed and inseminated (Allen \& Champion, 1955; Beatty, 1960; Edwards, 1965; Roche 
et al., 1968; Beatty et al., 1969; O'Reilly et al., 1972) was reaffirmed in the present experiment by the observation that the $\mathrm{C}$ cock sired $34 \%$ of the offspring in competition with the $\mathrm{L}_{1}$ cock. Verification of genetic homozygosity of the $\mathrm{C}$ and $\mathrm{L}_{1}$ cocks ruled out heterozygosity as a possible cause for the disparity.

Evidence from Exp. III suggests that the total number of spermatozoa inseminated did not influence the proportion of offspring when the ratio of spermatozoa was $1 \mathrm{C}: 1 \mathrm{~L}_{1}$. Because an equal number of hens was inseminated in each of the three treatment groups for each mixture of spermatozoa, the variability for percentage of offspring sired by the $\mathrm{C}$ male must be attributed to chance due to the relatively small number of observations. It is unlikely that insemination with as few as $100 \times 10^{6}$ spermatozoa influenced the proportion of offspring from each cock because $62 \%$ of the eggs were fertilized of those collected during the 10 days following insemination of $40 \times 10^{6}$ spermatozoa from the $\mathrm{C}$ or $\mathrm{L}_{1}$ male.

When an equal number of spermatozoa from rabbits (Beatty, 1960) or bulls (Beatty et al., 1969; Stewart et al., 1974) was inseminated heterospermically over a period of several months, the proportion of offspring sired by the competing males remained constant. Our data (Table 1) confirm this observation on constancy of proportions of offspring over a period of time. When a $1 \mathrm{G}: 2 \mathrm{~L}_{1}, 1.5 \mathrm{C}: 1.5 \mathrm{~L}_{1}$ or $2 \mathrm{C}: 1 \mathrm{~L}_{1}$ ratio of spermatozoa was inseminated, the proportion of offspring for a particular ratio did not change from May to September. Experiments involving $\mathrm{G}$ and $\mathrm{L}_{1}$ males were conducted over a period of 20 months and, except for Exp. VI, the relative fertility values $(x)$ did not differ $(P>0.05)$. The possible cause for the difference in Exp. VI is unknown. Overall, $L_{1}$ sired approximately 1.5 to 2 offspring for every offspring sired by the $\mathrm{C}$ male when $1 \mathrm{G}: 1 \mathrm{~L}_{1}$ sperm mixtures were inseminated. This indicates that season or age of males is unlikely to have a dramatic influence on the proportion of offspring for any sperm ratio.

The observation that the breed of hen did not influence the proportion of offspring sired by the two males agrees with those of Allen \& Champion (1955). They found that spermatozoa from a male did not have any particular affinity for fertilizing eggs of its breed or that of any other breed following heterospermic insemination using males of four breeds and three breeds of hens.

Spermatozoa may live in the reproductive tract of the hen for several weeks after insemination before fertilizing an egg. There is the possibility that spermatozoa from some males would lose fertilizing ability sooner than spermatozoa from other males. There was no difference in the proportion of offspring from a particular cock between the eggs laid soon after insemination and those laid later. This indicates that the heterospermic dominance of the $L_{1}$ male was not due to differential survival of the $G$ and $L_{1}$ spermatozoa in the hen.

Results from Exps I and II (Table 1) led us to believe that a possible mathematical relationship existed between ratios of spermatozoa and proportions of offspring. Such a relationship would not make it possible for the total quality of a semen mixture to be reduced to the level of the poorest component of the semen mixture as suggested by Van Drimmelen (1951). The data shown in Text-fig. 1 fail to indicate an interaction between semen samples from different 
males as suggested by Van Drimmelen (1951) but do indicate that ratios of spermatozoa and proportions of offspring are mathematically related. The curves in Text-fig. 1, as calculated by the maximum likelihood method, can be closely approximated by the following simple equation:

$\% \mathrm{C}$ offspring calculated $=$

$\frac{100(\% \mathrm{G} \text { offspring from } 1 \mathrm{C}: 1 \mathrm{~L} \text { sperm ratio) }(\% \mathrm{C} \text { sperm in calculated ratio) }}{(\% \mathrm{C} \text { offspring from } 1 \mathrm{C}: 1 \mathrm{~L} \text { sperm ratio) }(\% \mathrm{C} \text { sperm in calculated ratio) }+}$

The curves in Text-fig. 1 indicate that once the proportion of offspring sired by competing males is established for any given ratio of spermatozoa, the proportion of offspring for any other ratio can be predicted quite precisely. The observed data in Exps I and II for proportions of offspring from mixtures of spermatozoa in ratios of $1 \mathrm{C}: 2 \mathrm{~L}_{1}, 1.5 \mathrm{C}: 1.5 \mathrm{~L}_{1}$ and $2 \mathrm{C}: 1 \mathrm{~L}_{1}$ support this conclusion. Conversely, the ratio of spermatozoa for any desired proportion of offspring can also be estimated. Heterospermic dominance can then be established by simply inseminating any known ratio of spermatozoa, observing the proportion of offspring, and calculating the proportion of offspring that would result from inseminating a mixture with equal numbers of spermatozoa.

These experiments have shown that, in the domestic fowl, the age of males, season, total numbers of spermatozoa, breed of hen and the length of time spermatozoa are in the female tract did not affect the proportions of offspring sired by each male following heterospermic insemination. The proportion of offspring, however, did change quite predictably when the ratios of spermatozoa from each male were changed.

\section{ACKNOWLEDGMENTS}

The authors are grateful to Dr D. J. Bray for providing hens and cocks and to Mr R. R. Marsh for their care and management.

\section{REFERENCES}

Arten, C. J. \& Champion, L. R. (1955) Competitive fertilization in the fowl. Poult. Sci. 34, 1332.

BeatTy, R. A. (1957) A pilot experiment with heterospermic insemination in the rabbit. $\mathcal{F}$. Genet. 55, 325.

BeAtTy, R. A. (1960) Fertility of mixed semen from different rabbits. F. Reprod. Fert. 1, 52.

Beatty, R. A., Bennett, G. H., Hall, J. G., Hancock, J. L. \& Stewart, D. L. (1969) An experiment with heterospermic insemination in cattle. 7. Reprod. Fert. 19, 491.

Bonnier, G. \& Trulsson, S. (1939) Selective fertilization in poultry. Hereditas, 25, 65.

Burrows, W. H. \& Quinn, J. P. (1939) Artificial Insemination of Chickens and Turkeys. U.S. Dept. Agric. Circ. No. 525.

CoLE, L. J. \& DAvis, C. L. (1914) The effect of alcohol on the male germ cells, studied by means of double matings. Science, $\mathcal{N} . r .39,476$.

Dunn, L. G. (1927) Selective fertilization in fowls. Poult. Sci. 6, 201.

Dzruk, P. J. (1965) Double mating of rabbits to determine capacitation time. F. Reprod. Fert. 10, 389.

EDWARDs, R. G. (1965) Selective fertilization following the use of sperm mixtures in the mouse. Nature, Lond. 175, 215.

O'Reilly, P. J., Graves, C. N. \& Dziuk, P. J. (1972) Heterospermic insemination as a means of evaluating techniques of semen handling. 7. Reprod. Fert. $29,49$.

Roberts, E. \& Dawson, W. N. (1935) Effect of Fowler solution on animals. Bull. Ill. agric. Exp. Stn, 413.

Roche, J. F., Dziuk, P. J. \& Lodge, J. R. (1968) Competition between fresh and aged spermatozoa in fertilizing rabbit eggs. F. Reprod. Fert. 16, 155. 
Stewart, D. L., Spooner, R. L., Bennett, G. H., Beatty, R. A. \& Hancock, J. L. (1974) A second experiment with heterospermic insemination in cattle. F. Reprod. Fert. 36, 107.

Sumption, L. J. (1961) Multiple sire mating in swine: evidence of natural selection for mating efficiency. 7. agric. Sci., Camb. 56, 31.

VAN Drmmelen, G. C. (1951) Artificial insemination of birds by the intraperitoneal route. Onderstepoort 7. vet. Res. Suppl. 1. 